\title{
Thoracic trauma - principals of surgical management
}

\author{
Jerzy Lasek @ , Eugeniusz Jadczuk \\ ${ }^{1}$ Department of Health Sciences, Pomeranian University in Słupsk, Poland
}

\begin{abstract}
Thoracic trauma continues to be a significant surgical problem. It is estimated that $25 \%$ of trauma-related deaths are due to penetrating and blunt thoracic injuries. Principals of surgical management of specific thoracic injuries like: tension pneumothorax, open pneumothorax, massive haemothorax, flail chest, cardiac injuries, ruptures of the aorta, tracheobronchial tree lesions, oesophageal and diaphragmatic injuries have been reviewed. Awareness of the potential for deterioration and early correct identification of life threatening thoracic injuries are the keys to successful management. Good outcomes in the management of thoracic injuries depend on rapid transport of the injured patient to the hospital, effective diagnostic and therapeutic measures and an aggressive involvement of an experienced surgical team, optimally in the operating theatre. Successful management of these injuries depends on effective prioritisation of procedures based on the $A B C$ principals combined with a rapid diagnosis of severe injuries and aggressive surgical treatment of life-threatening lesions following penetrating and blunt trauma. Rapid decompression of tension pneumothorax and emergency thoracotomy, especially in patients following penetrating thoracic trauma may result in good outcomes. Effective management of severe thoracic injuries requires an integrated approach and cooperation of a multidisciplinary trauma team, including experienced thoracic and cardiac surgeons.
\end{abstract}

Keywords: penetrating $\cdot$ blunt $\cdot$ thoracic $\cdot$ trauma $\cdot$ surgery

\section{Citation}

Lasek J, Jadczuk E. Thoracic trauma - principals of surgical management. Eur J Transl Clin Med. 2020;3(1):66-73.

DOI: $10.31373 /$ ejtcm/120124

\section{Overview of thoratic trauma}

Thoracic trauma constitutes to be a significant medical problem and a major challenge for surgeons. It is estimated that $25 \%$ of road traffic accident-related deaths are due to thoracic lesions. Many of these pa- tients die immediately at the scene because of rapid exsanguination secondary to rupture of the aorta or major vessels. Some patients die later as a consequence of acute respiratory distress syndrome (ARDS), multiple organ failure (MOF) and sepsis [1-2]. Lung is a very sensitive target organ for secondary injury fol-

Corresponding author:

Jerzy Lasek, Department of Health Sciences, Pomeranian University in Słupsk, Poland

e-mail: jerzy.lasek@gumed.edu.pl

No external funds.

Available online: www.eitcm.gumed.edu.pl

Copyright $®$ Medical University of Gdańsk

This is Open Access article distributed under the terms of the Creative Commons Attribution-ShareAlike 4.0 International. 
lowing shock and remote tissue alterations. Tissue damage and shock can activate an inflammatory cascade which contributes to pulmonary insufficiency. Patients who reach hospital sometimes die as a consequence of misassessment, delay in treatment and other inadequacies; these are preventable deaths. It was found that a significant percent of in-hospital deaths from thoracic trauma were preventable, with injuries either not being recognized, diagnosed with delay or being inadequately treated [1, 3].

Thoracic trauma is quite frequent in Poland. In a large study from Poland, thoracic injuries were diagnosed in about $25 \%$ of 681 lethally-injured patients who were treated at a university trauma department [1]. These injuries were found as isolated chest lesions or components of multiple injuries localized in different anatomical regions and contributing significantly to the mortality [1]. Other studies suggest that $50 \%$ of patients who died in the pre-hospital phase had severe thoracic injuries. Severe vascular lacerations causing massive haemorrhage to pleural cavities and mediastinum were combined with vast injuries of the abdominal organs, brain and bone fractures [2-3].

\section{Treatment challenges}

Successful treatment of thoracic trauma continues to be challenging. It depends on optimal and effective prioritization of management based on the principals of $A B C$, with a rapid identification of severe injuries and aggressive surgical treatment of life-threatening injuries [4].

Thoracic injuries are usually classified as penetrating or blunt, the latter encompassing direct trauma as well as crush, acceleration or deceleration and blast injuries. In patients with polytrauma, life-threatening injuries that are without obvious external signs may be missed as attention is paid to more visible but less clinically serious injuries. Penetrating trauma may cause pneumothorax or haemothorax with massive blood loss. Some patients after chest trauma deteriorate rapidly. But on the other hand, with proper management they can rapidly improve. In patients with penetrating injuries surgical operations are frequently indicated, while diagnostic investigations are less required than in blunt trauma. In some cases, the distinction between blunt and penetrating thoracic trauma should be based on high index of suspicion because penetrating injuries often coexist with severe blunt injuries of solid organs and major vessels [4].

Careful analysis of patterns and mechanisms of chest injuries may be helpful in some situations. It has been proven that:
A) penetrating thoracic trauma is usually connected with laceration of the heart, major vessels, intercostal vessels, airways, lung, oesophagus and diaphragm; there is also a risk of trauma to adjacent organs in the abdominal cavity (spleen, liver) and retroperitoneal space (major vessels, kidneys) [5],

B) blunt thoracic trauma may cause cardiac contusion, lung contusion, rib fractures, thoracic spine fractures,

C) crush mechanism may cause rupture of bronchus, oesophagus, heart, lung contusion, rib fractures with or without flail chest,

D) deceleration thoracic trauma may cause aortic rupture, airway damage, diaphragmatic rupture,

E) blast mechanism may be responsible for disruption of any intrathoracic organ and vessel.

Regardless of its mechanism and pattern, the main consequence of thoracic trauma is reduction of vital functions such as respiration and circulation, leading to hypoxia, hypovolaemia, reduced cardiac output. The sequelae of this injury have a detrimental effect on organs beyond the chest cavity, e.g. kidneys, liver, brain, gastro-intestinal tract.

In Poland, penetrating thoracic trauma is most often the result of knife injury. Knife wounds usually are connected with low velocity penetration and mortality is strictly related to the injured organ [1]. Compared with other countries, the occurrence of firear$\mathrm{m}$-related penetrating injuries in Poland is sporadic. Firearm injuries cause more extensive tissue destruction related to the kinetic energy. Bullets are designed so that on impact, the missile expands or shatters, imparting all its energy to the tissue. Other ballistic characteristics of the bullet may contribute to tissue damage e.g. yaw, tumble and pitch. Tumbling may be important in high-velocity weapons, i.e. over $800 \mathrm{~m} / \mathrm{s}$. Shotgun blasts are very dangerous because all of the energy is transferred to the tissue [4].

Patients with penetrating thoracic injuries to the mid-torso require an aggressive surgical approach, especially those with anterior wounds. If the wound does not obviously penetrate the abdomen, an option is to explore the wound under local anaesthesia whether or not it has penetrated the peritoneal cavity or retroperitoneal space. If peritoneal penetration has occurred, laparotomy is mandatory in order to find all possible injuries. For stable patients following thoracic trauma, options include other diagnostic measures like thoracoscopy and laparoscopy [6].

Patients following chest trauma arrive to hospitals in two physiological states: haemodynamically unstable or haemodynamically stable. The state of the 
patient determines the specific diagnostic and therapeutic approach. The initial assessment of any injured patient must place priority on the evaluation of the airway and the adequacy of the cardiovascular system according to the $A B C$ algorithm. A rapid physical examination will determine if the patient is cyanotic, tachypneic or has other problems with respiration. In the patient with a penetrating or a blunt injury to the upper torso who is unstable, most probably haemorrhage is occurring into the chest cavity; the patient should be taken to the hospital with no delay. It is important to insert a chest tube as soon as possible (through the 4-th or 5-th intercostal space) during the initial assessment and resuscitation in the emergency department. Bilateral chest tubes may be indicated. A chest $x$-ray is not required to insert a chest tube, but it is useful to do in order to confirm tube placement [7-8].

\section{FAST or CT}

Focused Assessment with Sonography for Trauma (FAST) has been widely used in trauma centers and emergency departments. It is a rapid, non-invasive, ultrasound diagnostic protocol used both in hamodynamically unstable and stable patients with penetrating or blunt injuries. It is usually performed in the resuscitation area of the Emergency Department. The extended FAST protocol (eFAST) may be very valuable in identifying cardiac tamponade, haemothorax and haemoperitoneum $[2,4]$. In patients who are haemodynamically stable, a plain anteroposterior (AP) chest radiograph is still a gold diagnostic standard to identify pneumothorax or haemothorax. The eFAST examination should be performed within 10 minutes since the patient's arrival at the emergency department. A thoracic radiograph before placement of a chest tube may be helpful in excluding rupture of a diaphragm with possible herniation of a stomach or intestines to the pleural cavity, especially in patients following blunt trauma. Clinical signs in patients with chest injuries sometimes are subtle or misleading. Therefore, the thoracic radiograph helps to identify important lesions which require emergency surgical intervention or may suggest further investigations such as: CT scan, FAST, Transoesophageal Echocardiography (TEE) or thoracoscopy and laparoscopy [9-11].

Whole body computerized tomography (WBCT, also referred to as polytrauma scan) is a widely accepted diagnostic tool in the primary management of patients following major trauma. In many institutions WBCT is indicated even when the patient is haemodynamically unstable, as it may identify severe injuries within minutes [12]. WBCT is particularly recommended in pa- tients after blunt trauma and with suspected multiple injuries, as it can reveal occult thoracic lesions [11].

\section{Specific thoracic injuries}

Management of specific thoracic injuries depends on the state of a patient arriving to the emergency department. Clinically, thoracic injuries are divided into two types: immediately life-threatening and potentially life-threatening (see Table 1).

Table 1. Thoracic injuries divided by their urgency

\begin{tabular}{|c|c|}
\hline $\begin{array}{c}\text { Immediately } \\
\text { life-threatening } \\
\text { injuries }\end{array}$ & $\begin{array}{c}\text { Potentially } \\
\text { life-threatening } \\
\text { injuries }\end{array}$ \\
\hline 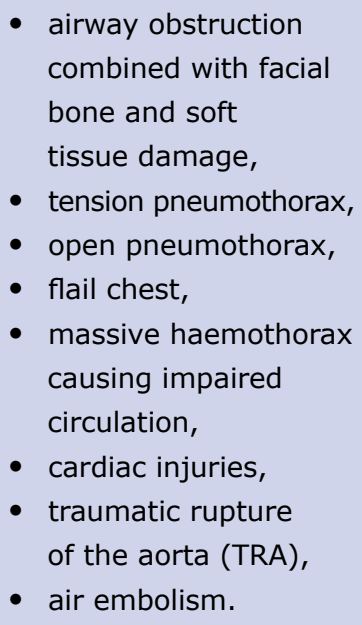 & $\begin{array}{l}\text { - } \text { myocardial } \\
\text { - } \text { pulmontusion, } \\
\text { contusion, } \\
\text { - traumatic } \\
\text { diaphragmatic } \\
\text { herniatiom (TDH), } \\
\text { tracheobronchial } \\
\text { - } \text { tree disruption, } \\
\text { - } \text { simple pneumothorax, } \\
\text { - oesophageal } \\
\text { disruption }\end{array}$ \\
\hline
\end{tabular}

\section{Immediately life-threating injuries}

It is critical to identify and treat airway obstruction as soon as possible during the primary survey at the Emergency Department. Tension pneumothorax causes a real threat to life because of the progressive build-up of air within the pleural cavity, caused by one-way leak from a lacerated lung, airway or a chest wall. Air enters the pleural space on inspiration, but cannot be evacuated during expiration due to the functioning of one-way flap valve. This creates progressive accumulation of air with collapse of the ipsilateral lung, causing severe hypoxia, shift of the mediastinum to the opposite side, compression of the contralateral lung with atelectasis and decreasing venous return to the heart. The combination of hypoxia, impaired ventilation and 
critically reduced cardiac output leads to traumatic cardiac arrest unless the tension is decompressed. Tension pneumothorax can complicate both penetrating and blunt trauma. It may be also induced iatrogenically during the insertion of central venous lines or by the incorrect application of occlusive dressings to penetrating chest wall wounds. It should be remembered that tension pneumothorax may be intitiated in patients with a simple pneumothorax who are put on positive pressure ventilation. Awareness of this potential for the deterioration and early identification and treatment are the key to effective management. Diagnosis of a tension pneumothorax should be based on physical examination and radiological examinations should not be performed $[3,7]$. The diagnosis can be difficult in a noisy emergency department. The classic signs are connected with decreased or lack of breath sounds and percussion tympany on the ipsilateral side, tracheal and cardiac deviation to the contralateral side, reduced chest movements, elevated venous pressure, progressive tachycardia, hypotension with pulsus paradoxus. When untreated, this pathology leads to full circulatory collapse and cardiac arrest with pulseless electrical activity (PEA). In rare cases tension pneumthorax may be bilateral.

\section{Tension pneumothorax}

Tension pneumothorax is the most frequent reversible cause of death during resuscitation of patients in pre-hospital traumatic cardiac arrest [13]. In the patient who is dying there should be no hesitation in performing immediate decompression of the affected side, converting tension pneumothorax into an open pneumothorax or simple pneumothorax [7-8]. In emergency the decompression is achieved by insertion of a dedicated needle (or a large-caliber, e.g. 16 gauge intravenous catheter) into the fifth intercostal space in the anterior axillary line. The hiss of air usually confirms decompression and clinical improvement should be noticed. The cannula should be left open (resulting in an open pneumothorax) and the next step is to insert a chest tube, followed by re-examination of the chest and an AP chest radiograph. It must be remembered that a needle thoracostomy can easily become kinked or displaced, allowing the tension pneumothorax to recur. One should also keep in mind that the inserted drain may be blocked. It is obvious that these patients need careful clinical monitoring and repeated clinical examination $[4,13]$.

\section{Massive haemothorax}

Massive haemothorax is another life-threatening condition. Intercostal and internal mammary vessels are commonly disrupted. It should be remembered that each hemithorax can hold up to $3 \mathrm{I}$. of blood. It is estimated that approximately $50 \%$ of patients with hilar, great vessel or cardiac wounds die immediately after the injury, while about $25 \%$ survive for about 5-6 minutes; these are pre-hospital deaths. The remaining 25\% arrive at the Emergency Department alive and require immediate diagnosis and surgical treatment. The diagnosis of massive haemothorax is invariably made by the presence of shock, respiratory insufficiency and deviation of the mediastinum. Patients in shock and with respiratory insufficiency must be intubated with no delay. A chest radiogram may confirm also the amount of blood loss. A chest tube should be inserted in order to relieve the threat of ventilatory embarrassment. The main objective in the treatment of massive haemothorax is to restore blood volume, treating actively shock together with drainage of the haemothorax via an intercostally inserted chest tube. In majortity of the patients with haemothorax the proper placement of a chest tube allows for effective evacuation of the blood. However, if initial drainage of blood is $>1500$ $\mathrm{ml}$ or ongoing drainage is $>200 \mathrm{ml} / \mathrm{h}$ for about 4 or more hours, then thoracotomy in the surgical theatre is likely to be required. Ongoing bleeding, patient's clinical status and requirement for blood transfusion are important parameters that should be taken into consideration deciding about the need for the thoracotomy. In the operated patients major vessels, intercostal arteries, injury to the hilum of the lung or to the myocardium are the main sources of massive bleeding. These injuries should be treated by oversewing the lesion, making sure that bleeding is controlled [7-8]. In some instances resection of the lung segment or lobe and even pneumonectomy may be necessary $[3,14]$.

Injuries of the chest wall are common in patients following blunt trauma causing multiple fractures both in anterior and posterior parts of the ribs. When the chest wall loses its bony stability within thoracic cage, it becomes flail and starts to move paradoxically. The flail segment is moving in the direction opposite to the stable chest wall during inspiration and expiration. In many patients multiple rib fractures are accompanied by significant blood loss and lung contusion. Diagnosis of flail chest is based on clinical examination. In patients with flail chest, severe pulmonary contusion contributes to respiratory insufficiency. Treatment is usually initiated with high flow oxygen and lung expansion by intermittent positive pressure ventilation. Intercostal chest tubes are almost always necessary, particularly if positive pressure ventilation is needed. The aim of further management is to preserve respiratory function. In all patients effective pain relief is required, in some cases epidural anaesthesia may be very effective. Careful fluid management is indicated 
because injured lungs are extremely sensitive to inadequate perfusion and to fluid overload. In cases with respiratory distress and hypoxia due to the flail segment, endotracheal intubation and mechanical ventilation are necessary, particularly in patients with large pulmonary contusion. Currently, there is an increasing tendency to concentrate on the associated damage to the underlying lung in the form of pulmonary contusion and ARDS [15]. Internal stabilization by means of endotracheal intubation and mechanical ventilation are effective therapeutic options in patients with bilateral multiple rib fractures. Some patients with unilateral flail chest can be managed selectively with ventilatory assistance or with short term use of mechanical ventilation. It is imperative that these patients have vigorous pulmonary care (aggressive pulmonary hygiene and cough-deep breathing) and are treated in departments by experienced and skilled medical staff.

It should be remembered that rib fractures are independent predictors of other abdominal solid organ injuries (spleen, liver) [16]. Currently, operative reduction and fixation (ORIF) of the chest wall has been evolving as a method of chest wall stabilization [17]. ORIF of broken ribs may be performed in adult patients with flail chest with measured metal plates, bracketed fixators or resorbable plates. This approach improves primary and secondary outcomes in appropriately selected patients [18].

\section{Penetrating heart wounds}

Penetrating heart wounds represent some of the most extreme emergencies that a physician must manage. A penetrating cardiac trauma creates several rapid life threatening sequelae that include massive haemorrhage, cardiac tamponade and myocardial injury [19]. The period between trauma and successful therapeutic measures very often is dramatically short. More effective emergency medical response systems have resulted in more opportunities to treat these severely injured patients at the hospital. It is estimated that at least about $50 \%$ of patients with a penetrating cardiac injury may reach the trauma unit alive with an opportunity to be treated and finally salvaged.

Whatever the cause of penetrating injuries to the heart, a series of events occurs that can compromise cardiac function and quickly cause death unless timely interventions are instituted. The first problem is the penetration of a cardiac chamber, which leads to bleeding. If a large damage to the pericardium is made, bleeding into either chest cavity or mediastinum may occur; thus hypovolaemic shock may occur without cardiac tamponade. If the pericardial damage is small or seals itself, cardiac tamponade may develop with physical signs of hypotension, distended neck veins and muffled heart sounds (Beck's triad). In such a situation, a small amount of blood in the pericardial space can cause serious cardiovascular instability by restricted venous return and thus "choking" the heart. In other cases, cardiac trauma may cause damage of the cardiac valves or ventricular septum and may lead to uncontrollable heart failure. The pericardial sac does not acutely distend; 75$100 \mathrm{ml}$ of blood can produce a life-threatening tamponade in the adult. The classic Beck's triad is not always seen in the Emergency Department; neck veins may not be distended in deep hypovolaemia and muffled heart sounds can be difficult to identify in noisy surroundings.

It seems that penetrating cardiac injuries should be easy to diagnose. In reality it happens that such an injury may be overlooked, especially in fully-clothed, drunk or unconscious patients with other coexisting lesions. Therefore, it is imperative that all members of the emergency services and surgeons should treat these patients with a high degree of suspicion starting from the scene of the trauma. The patient should be taken to the hospital as soon as possible according to the "scoop and run" (or "load and go") approach and immediate emergency thoracotomy should be initiated [20-21]. Ideally an emergency thoracotomy should be performed in the operating theatre, however if the patient is in extremis, this life-saving procedure can be performed in an Emergency Department. A left anterolateral thoracotomy through the 4-th or 5-th intercostal space and long pericardial incision anterior to the phrenic nerve allows good exposure of the heart for control of haemorrhage and provides the optimal access for direct compressions of the heart during resuscitation. This surgical access is made in the supine position of a patient and may be extended across the sternum into the contralateral hemithorax (the "clamshell" incision or bilateral thoracotomy). Majority of cardiac wounds can be surgically closed with simple sutures or horizontal mattress sutures of a $3 / 0$ or $4 / 0$ monofilament. Bolstering the sutures with Teflon pledgets may be required. Care must be taken not to suture coronary vessels. Loose approximating sutures of the pericardium after the injury is repaired prevent from a serious complication connected with the cardiac herniation through the pericardium, which may occlude venous return and cause sudden death. In case of damage to the valves, chordae tendineae, septum or myocardium, further cardiac surgery may be needed.

\section{Tears of the aorta or pulmonary arteries}

Tears of the aorta or pulmonary arteries are associated with blunt or rapid deceleration mechanism such as falls from significant height, high speed motor vehicle crashes. The aorta may be transected comple- 
tely or partially. The most common site of rupture is at the attachment of the ligamentum arteriosum. It is estimated that aortic rupture is immediately fatal in about $85-90 \%$ and accounts for $15-20 \%$ of immediate overall trauma deaths due to road traffic accidents. The immediate survival of the patient depends on the development of a contained haematoma, maintained by the intact adventitia. The survival of the patient after reaching the hospital depends on early diagnosis followed by effective treatment. Any suspicion of an aortic injury necessitates further rapid investigation. A widened mediastinum over $8 \mathrm{~cm}$ at the level of aortic arch is the most consistent finding on a chest radiogram. Contrast-enhanced spiral CT scan has become the investigation of choice for the proper diagnosis of aortic injuries with sensitivity and specificity approaching $100 \%$. When this lesion is suspected, intended permissive hypotension should reduce the risk of a rupture of the adventitial layer containing the tear. The goal for systolic blood pressure should be approximately $90-100 \mathrm{~mm} \mathrm{Hg}$. Alpha and $\beta$ blockade (e.g. esmolol, labetolol, nitropusside) should be instituted after significant bleeding from other injuries has been excluded. Currently the treatment of traumatic rupture of the aorta has evolved from performing emergent open surgical repair with clamping and sewing technique to minimally invasive treatment by means of interventional radiologic technique with the interposition of a vascular intra-aortic stent graft [22-23].

\section{Potentially life-threatening injuries}

Most patients with major tracheobronchial tree and airway injuries die at the scene as a result of asphyxia. Those who survive to reach the hospital are usually in extremis. These lesions are suggested by massive haematoptysis, airway obstruction, progressive mediastinal air, subcutaneous emphysema, significant persistent air leak after placement of a chest tube. In most cases the air leak stops after a few days (combined with good expansion of the lung) with the chest tube drainage alone. If there is a persistent leak of air for a long time, thoracic CT and bronchoscopy are indicated to detect the damage. In case of damage to the trachea or bronchus, a posterolatertal thoracotomy is needed. Definitive treatment includes primary repair with absorbable sutures. It should be remembered that chest drainage is required in case of any pneumothorax [24].

\section{Diaphragmatic injuries}

Diaphragmatic injuries occur in patients following violent abdominal and thoracic compression mechanism. The left diaphragm is injured 6 times more frequently than the right one. The diaphragm normally rises to the fifth intercostal space during normal expiration, so that any patient after mid-torso trauma is at risk for diaphragmatic rupture. Right-sided lesion may show only a raised hemidiaphragm, whereas a left-sided may show herniation of the stomach, spleen and intestines. Accurate diagnosis is obtained optimally on thoraco-abdominal CT or NMR. All diaphragmatic ruptures should be repaired. Those injuries that are not repaired will present later, usually with dangerous incarceration of the small bowel, colon or omentum into the hernial defect. Acute repair may be accomplished via laparotomy or thoracotomy. The preferred surgical closure of diaphragmatic ruptures is based on interrupted sutures. In large defects synthetic prosthetic material or flaps should be used [25-26].

\section{Oesophageal injuries}

Oesophageal injuries are usually caused by penetrating trauma. The diagnosis is also probable in patients after blunt trauma with pneumothorax or haemothorax in the absence of rib fractures. On chest $X$-ray, patients may present posterior mediastinitis with fever, pain and persistent pneumothorax. Once diagnosed, posterolateral thoracotomy and routine surgical closure should be performed. Injuries to the oesophagus should be surgically repaired if the injury is less than 6 hours "old". It is important to put the sutures in situ in order to avoid damage to the vasculature of the oesophagus. In "older" oesophageal injuries wide drainage with chest tubes, diverting oesophagostomy and nutritional support by feeding gastrostomy may provide the optimal management [4].

Strict criteria for emergency department thoracotomy (EDT) (historically called "emergency room thoracotomy") remain controversial. Overall survival rates for patients undergoing ED thoracotomy vary from 4 to $33 \%$ across numerous studies [27-28]. This procedure should be reserved to control haemorrhage, to control the aortic outflow (aortic "cross-clamping") and to perform direct cardiac compressions. There should be no hesitation to perform EDT in patients with cardiac arrest after penetrating trauma. EDT must be initiated only in intubated patients. It should be also started if only pulseless electrical activity (PEA) has been recorded. EDT has been found most effective in penetrating cardiac wounds, especially when cardiac tamponade is present and in those patients in whom there has been a witnessed post traumatic cardiac arrest [29]. The most common surgical access for this procedure is through the 4-th or 5-th left intercostal space. The incision when needed may be extended to the opposite side ("clamshell" incision) providing good access to the 
heart, mediastinum and both pleural cavities. Median sternotomy gives excellent exposure to the heart and great vessels. EDT is contraindicated when there has been ineffective cardiopulmonary resuscitation (CPR) for more than 10 minutes with or without endotracheal intubation and in cases, when there were no signs of life at the scene. EDT is a team event. This procedure should be terminated if irrepairable cardiac damage has occurred, pulseless electrical activity (PEA) and asystolic cardiac arrest have occurred for over 10 minutes.

The survival rate in patients following EDT after penetrating thoracic trauma is about $10 \%$, but it has been found beneficial in around $50 \%$ in patients presenting with signs of life after isolated penetrating cardiac injuries and only rarely in those presenting without signs of life (below 2\%). In non-cardiac penetrating wounds the survival rate is around $25 \%$ when signs of life were noticed. Only $1-2 \%$ of patients after EDT are salvaged after blunt trauma regardless their clinical status on admission. However, a patient after blunt trauma who is exsanguinating via a chest tube due to ruptured thoracic vessels may be salvageable with EDT. Whatever the indication, EDT should be performed by an experienced surgeon, optimally in the operating theatre with good lighting, appropriate instruments and a functioning suction apparatus. It must be noticed that there is an extremely high mortality rate associated with all thoracotomies performed anywhere outside the operating theatre, especially when performed by non-surgeons $[7,29]$. A candidate for an EDT should be by all means transported as soon as possible to the trauma center or to a surgical department providing professional trauma surgical approach [30-31].

Effective management of severe thoracic injuries demands integrated approach and necessity of cooperation of a multidisciplinary trauma team or an extended trauma team with the participation of experienced thoracic and cardiac surgeons.

\section{References}

1. Lasek J. Krytyczna ocean przyczyn śmiertelności 681 chorych, którzy zmarli po urazie spośród 20540 osób leczonych w Katedrze i Klinice Chirurgii Urazowej AM w Gdańsku w okresie 20 lat. Rozprawa habilitacyjna. Ann Acad Medicae Gedanensis [Internet]. 2000;XXX(suppl. 3):1-307. Available from: https://pbc.gda.pl/dlibra/publication/57980/edition/51883

2. Zhang S, Tang M, Ma J, Yang J, Qin X, Jin W, et al. Thoracic trauma - a descriptive review of 4168 consecutive cases in East China. Medicine (Baltimore) [Internet]. 2019 Apr;98(14):e14993. Available from: http://journals.Iww.com/00005792201904050-00018

3. Platz JJ, Fabricant L, Norotsky M. Thoracic Trauma. Surg Clin North Am [Internet]. 2017 Aug;97(4):783-99. Available from: https://doi.org/10.1016/i.suc.2017.03.004

4. Blyth A. Thoracic Trauma. In: Skinner D, Driskoll P, editors. ABC of major trauma [Internet]. 4th ed. Wiley-Blackwell; 2018. p. 18-28. Available from: https://www.wiley.com/en-pl/ABC+of+Major+Trauma,+4th+Edition-p-9780727918598

5. Berg RJ, Karamanos E, Inaba K, Okoye O, Teixeira PG, Demetriades D. The persistent diagnostic challenge of thoracoabdominal stab wounds. J Trauma Acute Care Surg [Internet]. 2014 Feb;76(2):418-23. Available from: https://journals.Iww. com/itrauma/Fulltext/2014/02000/The persistent diagnostic challenge of.23.aspx

6. Jin J, Song B, Lei Y, Leng X. Video-assisted thoracoscopic surgery for penetrating thoracic trauma. Chinese J Traumatol [Internet]. 2015 Feb;18(1):39-40. Available from: http://www.sciencedirect.com/science/article/pii/S1008127515000085

7. Hirshberg A, Mattox KL. The Chest. In: Allen M, editor. Top knife, the art of trauma surgery [Internet]. 2005. p. $147-81$. Available from: https://epdf.pub/queue/top-knife-art-and-craft-in-trauma-surgery.html

8. Ludwig C, Koryllos A. Management of chest trauma. J Thorac Dis [Internet]. 2017 Apr;9(S3):S172-7. Available from: https://pubmed.ncbi.nlm.nih.gov/28446982

9. Subcommittee A, Tchorz KM, Group IAW. Advanced trauma life support (ATLS $\left.{ }^{\circledR}\right)$ : the ninth edition. J Trauma Acute Care Surg. 2013;74(5):1363.

10. Saillant NN, Sein V. Management of severe chest wall trauma. J Emerg Crit Care Med [Internet]. 2018 May;2:41-8. Available from: http://jeccm.amegroups.com/article/view/4306/4900

11. Leech C. Whole body computed tomography for trauma: friend or foe? Emerg Med J [Internet]. 2017 Oct 1;34(10):635-6. Available from: http://emj.bmj.com/content/34/10/635.abstract

12. Huber-Wagner S, Biberthaler P, Häberle S, Wierer M, Dobritz M, Rummeny E, et al. Whole-Body CT in Haemodynamically Unstable Severely Injured Patients - A Retrospective, Multicentre Study. Landoni G, editor. PLoS One [Internet]. 2013 Jul 24;8(7):e68880. Available from: https://dx.plos.org/10.1371/journal.pone.0068880 
13. Mistry N, Bleetman A, Roberts KJ. Chest decompression during the resuscitation of patients in prehospital traumatic cardiac arrest. Emerg Med J [Internet]. 2009 Oct 1;26(10):738-40. Available from: http://emj.bmj.com/content/26/10/738.abstract

14. Phillips B, Turco L, Mirzaie M, Fernandez C. Trauma pneumonectomy: A narrative review. Int J Surg [Internet]. 2017 Oct;46:71-4. Available from: http://www.sciencedirect.com/science/article/pii/S174391911731230X

15. Qi Y. Clinical study on VATS combined mechanical ventilation treatment of ARDS secondary to severe chest trauma. Exp Ther Med [Internet]. 2016 Aug;12(2):1034-8. Available from: https://www.spandidos-publications.com/10.3892/ etm.2016.3355

16. Subedi N. Liver and Spleen Injuries and Associated Rib Fractures: An Autopsy Study. J Forensic Res [Internet]. 2014;5(5):240-5. Available from: https://www.omicsonline.org/open-access/liver-and-spleen-injuries-and-associated-rib-fractures-an-autopsy-study-2157-7145.1000240.php?aid=30426

17. Pieracci FM, Majercik S, Ali-Osman F, Ang D, Doben A, Edwards JG, et al. Consensus statement: Surgical stabilization of rib fractures rib fracture colloquium clinical practice guidelines. Injury [Internet]. 2017 Feb;48(2):307-21. Available from: http://www.sciencedirect.com/science/article/pii/S0020138316307665

18. Senekjian L, Nirula R. Rib Fracture Fixation. Crit Care Clin [Internet]. 2017 Jan 1;33(1):153-65. Available from: https://doi. org/10.1016/i.ccc.2016.08.009

19. Stranch EW, Zarzaur BL, Savage SA. Thinking outside the box: re-evaluating the approach to penetrating cardiac injuries. Eur J Trauma Emerg Surg [Internet]. 2017 Oct 18;43(5):617-22. Available from: https://doi.org/10.1007/s00068$\underline{016-0680-7}$

20. Davis JS, Satahoo SS, Butler FK, Dermer H, Naranjo D, Julien K, et al. An analysis of prehospital deaths. J Trauma Acute Care Surg [Internet]. 2014 Aug;77(2):213-8. Available from: https://journals.Iww.com/itrauma/Fulltext/2014/08000/ An analysis of prehospital deaths Who can we.5.aspx

21. Sanchez GP, Peng EWK, Marks R, Sarkar PK. 'Scoop and run' strategy for a resuscitative sternotomy following unstable penetrating chest injury. Interact Cardiovasc Thorac Surg [Internet]. 2010 Mar 1;10(3):467-8. Available from: https://doi. org/10.1510/icvts.2009.219865

22. Watanabe K, Fukuda I, Asari Y. Management of traumatic aortic rupture. Surg Today [Internet]. 2013 Dec 23;43(12):133946. Available from: https://doi.org/10.1007/s00595-012-0471-7

23. Karmy-Jones R, Jackson N, Long W, Simeone A. Current Management of Traumatic Rupture of the Descending Thoracic Aorta. Curr Cardiol Rev [Internet]. 2009 Aug 1;5(3):187-95. Available from: http://www.eurekaselect.com/openurl/content. php?genre $=$ article\&issn $=1573-403 \times \&$ volume $=5 \&$ issue $=3 \&$ spage $=187$

24. Madden BP. Evolutional trends in the management of tracheal and bronchial injuries. J Thorac Dis [Internet]. 2017 Jan;9(1):E67-70. Available from: https://pubmed.ncbi.nlm.nih.gov/28203439

25. McDonald AA, Robinson BRH, Alarcon L, Bosarge PL, Dorion H, Haut ER, et al. Evaluation and management of traumatic diaphragmatic injuries. J Trauma Acute Care Surg [Internet]. 2018 Jul;85(1):198-207. Available from: https://journals. Iww.com/itrauma/Fulltext/2018/07000/Evaluation and management of traumatic.31.aspx

26. Mizobuchi T, Iwai N, Kohno H, Okada N, Yoshioka T, Ebana H. Delayed diagnosis of traumatic diaphragmatic rupture. Gen Thorac Cardiovasc Surg [Internet]. 2009 Aug 24;57(8):430-2. Available from: https://doi.org/10.1007/s11748009-0418-0

27. Bouillon B, Probst C, Maegele M, Wafaisade A, Helm P, Mutschler M, et al. Schockraummanagement Polytrauma. Der Chir [Internet]. 2013 Sep 28;84(9):745-52. Available from: http://europepmc.org/abstract/MED/23979042

28. Boddaert G, Hornez E, De Lesquen H, Avramenko A, Grand B, MacBride T, et al. Resuscitation thoracotomy. J Visc Surg [Internet]. 2017 Dec;154:S35-41. Available from: http://www.sciencedirect.com/science/article/pii/ $\underline{\mathrm{S} 1878788617300826}$

29. Mollberg NM, Tabachnik D, Farjah F, Lin F-J, Vafa A, Abdelhady K, et al. Utilization of Cardiothoracic Surgeons for Operative Penetrating Thoracic Trauma and Its Impact on Clinical Outcomes. Ann Thorac Surg [Internet]. 2013 Aug;96(2):44550. Available from: http://www.sciencedirect.com/science/article/pii/S0003497513008461

30. Onat S, Ulku R, Avci A, Ates G, Ozcelik C. Urgent thoracotomy for penetrating chest trauma: Analysis of 158 patients of a single center. Injury [Internet]. 2011 Sep;42(9):900-4. Available from: http://www.sciencedirect.com/science/article/ pii/S0020138310001312

31. Seamon MJ, Haut ER, Van Arendonk K, Barbosa RR, Chiu WC, Dente CJ, et al. An evidence-based approach to patient selection for emergency department thoracotomy. J Trauma Acute Care Surg [Internet]. 2015 Jul;79(1):159-73. Available from: http://content.wkhealth.com/linkback/openurl?sid=WKPTLP:landingpage\&an=01586154-201507000-00024 